\title{
Heat IIIness - A Review of Military Experience (Part 1)
}

\author{
Maj MCM Bricknell \\ BM, MRCGP, DRCOG, DFFP, RAMC
}

Royal Army Medical College, Millbank, London SWIP 4RJ

\begin{abstract}
SUMMARY: This paper is the first part of a two part review of the published literature reporting the military experience of heat illness. It summarises current concepts of the mechanisms for the development of heat illness. The reports of heat illness in the military medical literature from pre-World War 1 to the end of World War 2 are discussed. The second part will consider reports from the end of the Second World War to the present day. Epidemiological evidence for the factors causing heat illness will be summarised and finally the current areas of uncertainty will be identified with proposals for future research.
\end{abstract}

\section{Introduction}

Death or disability due to the effects of heat has been an accompaniment to military training and operations ever since man first made war. There is now a large volume of research evidence to prove that heat illness in military personnel is caused by a combination of exercise and high environmental temperature. There are many factors that influence the balance of these two variables and these will be considered later. As a result of this association many military forces have invested considerable effort in creating guidelines to control physical exercise in high temperatures with the aim of reducing the number of heat casualties. This association has been extrapolated further by many civilian authorities to infer that all heat casualties in military personnel are preventable. It has therefore been claimed by some that a casualty can only occur as a consequence of negligence (1).

This paper is in two parts. It will review the research that has been conducted by military medical authorities around the world into the epidemiology of heat illness, aiming to establish that the majority of heat casualties could be prevented by the adherence to appropriate guidelines. Common sense by unit commanders being as important as externally imposed training restrictions. However a small proportion of heat casualties will always occur whatever limitations are placed on military training and this must be accepted.

Current concepts in the mechanisms for the development of the heat illnesses will firstly be summarised. A comprehensive review of the military medical literature will then be presented from pre World War 1 through to the experiences of the Second World War. The second part will review the literature from 1945 to the present day. The epidemiological evidence for the factors causing heat illness in the military setting will be summarised as will the international development of preventive measures. Finally current areas of uncertainty will be identified and some proposals for future research will be made.

\section{Review of Current Concepts of Heat Illness}

In order to understand the development of the military experience regarding the causation of heat illness it is necessary to review current concepts. Unfortunately there are no uniform definitions applied to the effects of heat and many different diagnostic labels have been used through the medical literature. The terms 'heat illnesses' are used to include all adverse effects on the body of a raised core temperature. The mildest of these is heat syncope which is fainting ascribed to the dilation of peripheral blood vessels resulting from raisef environmental temperature. Another mild condition is heat cramps which are random muscular cramps occurring during exercise in the heat. These seem to be associate with salt deficiency and may be helped by sato replacement. The more serious effects are heat exhaustion $\vec{c}$ and heatstroke. Heat exhaustion is usually defined when 8 of person becomes tired, thirsty, weak and develops headache, nausea or sickness in the presence of a rais environmental temperature. Sometimes a distinction is made between water-depletion heat exhaustion when the primary problem is a marked loss of water through sweating and salt-depletion heat exhaustion when the primary problem is the loss of salt through sweating. The former tends to develop rapidly, particularly when associated with exercise, whereas the latter tends to be more insidious when the salt losses are not replaced by the diet. However in practice it is difficult to distinguish between the two.

Heatstroke occurs when the core body temperature rises above $40-41^{\circ} \mathrm{C}\left(104-106^{\circ} \mathrm{F}\right)$ due to failure of the body's cooling systems. This has a multitude of serious effects on the brain, heart, liver and kidneys and can rapidly be fatal without treatment. The distinction between heatstroke and heat exhaustion in a collapsed casualty cannot often be made accurately. The first core temperature measured is frequently used to distinguish between the two conditions but as this may be measured some time after the problem has developed it is not necessarily a reliable indicator of the maximum core temperature sustained by the casualty. Similarly the factors that cause heat exhaustion, namely loss of water and salt through sweating, are the same as those that predispose to the development of heatstroke. Consequently many sources consider heat exhaustion and 
heatstroke to be part of a continuum of a disturbance of the body's ability to cope with a heat load.

Different authors have different inclusion criteria for subjects in their studies. Apart from the problem of diagnostic definitions, the other major variable is the setting of the study. At the most extreme there are a few studies that have been based on analysis of fatal heat casualties for which heatstroke will be the predominant condition. A large number of studies have assessed casualties admitted to hospital which clearly will exclude all mild cases. In both of these circumstances most of the information presented as been collected in retrospect and therefore there is a risk of loss of accuracy. The most complete analyses include all cases presenting for medical care which will therefore include most of the casualties that have become affected by the heat. The few studies that are based on primary care situations can ensure that the appropriate information is collected for analysis at the time of the incident. It is also possible to make an assessment of the incidence of heat casualties because the true population at risk can potentially be measured. A distinction between these types of studies will be made in this review.

The human body is in continual balance between the heat of the external environment and the heat generated internally through metabolism (M) such that the core temperature is maintained at approximately $37^{\circ} \mathrm{C}$. The human body looses heat by convection (C), conduction $(\mathrm{K})$, radiation $(\mathrm{R})$ and the evaporation of sweat $(\mathrm{E})$. The heat balance is traditionally expressed in the following equation.

$$
\text { HEAT GAIN }=\mathrm{M}+/-\mathrm{C}+/-\mathrm{K}+/-\mathrm{R}+/-\mathrm{E}
$$

In practice, for a person exercising or living in high temperatures, conduction, convection, and radiation have little effect. The evaporation of sweat being the prime mechanism by which the human body loses heat under conditions of heat stress.

The efficiency by which heat is lost to the environment depends on the 'cooling power' of that environment which can be measured in a variety of ways. One of the themes of military research into the effects of the heat has been the development of a measure of the physiological effect of environmental temperature. In essence there are three measures of environmental heat, the dry bulb temperature (DBT), the wet bulb temperature (WBT) and the globe temperature (GT). The dry bulb temperature is measured by a thermometer placed in the shade and this is the true air temperature. The wet bulb temperature is measured by a thermometer with the bulb enclosed in a wet wick. This may either be measured in the open air exposed to the wind or enclosed in a draft free box and thus shielded from the wind. The WBT measures the ability of the environment to cool by evaporation. This is affected by the air temperature, humidity and wind speed (for a WBT thermometer exposed to the wind). The relationship between the DBT, WBT, humidity and wind speed can be predicted from psychrometric charts. The difference between DBT and WBT is proportional to the humidity with the WBT being lower than the DBT unto $100 \%$ humidity when they are equal. The glob? thermometer is a thermometer placed into a globe that exposed to radiant heat. The globe may be black or m be covered by a material to represent the clothing exposed personnel. This measures the heating effect of the sun's radiation. A variety of mathematical combination of DBT, WBT and GT have been devised to create consolidated figure which represents the environment heat load. The most widely used of these is the Wet BuB Globe Temperature Index which will be discussed later this paper. A refinement of this integrated approach is the wet globe thermometer (WGT) which is a globe enclosed in a material that is kept wet with a wick. In principle this will integrate the WBT and the GT. The relationsh between DBT, WBT and GT that approximates to the physiological effects of environmental heat is an area military research that will be discussed.

\section{Pre-World War 1 Review}

The earliest record of a description of the sympton and signs of heat illness is present in the bible in the Book of Judith chapter VIII vv2 and 3: 'and her husband Manasses, who died in the time of the barley harvestof he was standing over the bound sheaves in the field; the heat came upon his head, and he died in Bethuliaing own city, and was buried there with his fathers' (2). The ancients associated this with Sirius, the dog star, which can be seen following the sun in the summer monghọ Indeed the condition was often called Siriasis utut modern times. The earliest record of the effects of affecting military operations comes from the Roman er In 24 BC Aelius Gallus conducted a military campaign Arabia. This account was written by Dio Cassius (A 150-235).

'While this was going on, another and a new campaig had its beginning and its end. It was conducted by Aelius Gallus, the governor of Egypt, against the country callet Arabia Felix, of which Sabos was king. At first Aeliw encountered no one, yet he did not proceed witho difficulty; for the desert, the sun, and the water (whici had some peculiar nature) all caused his men grea distress, so that a large part of the army perished. The malady proved to be unlike any of the common complaints, but attacked the head and caused it to parched, killing forthwith most of those who we attacked, but in the case of those who survived this stag it descended to the legs, skipping all the intervening parts of the body, and it caused dire injury to them. There was no remedy for it except a mixture of olive oil and wing both taken as a drink and used as an ointment; and the remedy naturally lay within reach of only a few of therfy since the country produces neither of these articles and this men had not an abundant supply of them beforehand. the midst of this trouble the barbarians also fell upofi them. For hitherto they had been defeated whenever they joined battle, and had even been losing some places; b 
now, with the disease as their ally, they not only won back their own possessions, but also drove the survivors of the expedition out of the country. These were the first of the Romans and, I believe, the only ones to traverse so much of Arabia for the purpose of making war; for they advanced as far as the place called Athlula, a famous locality (3).'

The development of ideas for the causation of heat illness is difficult to follow through the middle ages. Blancard's 'Physical dictionary' of 1693 gives a definition of siriasis; an inflammation or rather heat of the brain or its membranes occasioned by the heat of the sun. This is frequent in children because of the thinness of their skulls (4). It is clear that the association between the sun's heat and heat illness was being made, however the mechanism by which this occurred could only be related to the current knowledge of human physiology. The benefits of avoiding the rays of the sun were elucidated in 1744 by De Meyserey, a French army surgeon. He believed that by using white leather helmets the effects of the sun's heat could be prevented. 'Experience has shown that white bodies have the property of reflecting the sun's rays, and our white leather will be sufficiently impenetrable to these rays to prevent those unhappy accidents the fatal outcome of which we have too often noted (4).'

The first records of research into the physiological effects of heat are attributed to Blagden and Fordyce in 1775. They showed that men in good health could stand, for a period of fifteen minutes, an exposure to a dry atmospheric temperature of $250^{\circ} \mathrm{F}$ without feeling any ill effects or a serious rise in body temperature. A beefsteak exposed to the same environment was cooked in 13 minutes. But when in a damp room heated to $129.9^{\circ} \mathrm{F}$ $\left(54.4^{\circ} \mathrm{C}\right)$ their temperature rose to $100^{\circ} \mathrm{F}\left(37.8^{\circ} \mathrm{C}\right)$. This evidence established the relationship between heat and humidity in the ability of the body to lower core temperature by sweating (5). This physiological evidence was further refined by the physiologist Claude Bernard in an experiment in 1858 . He produced deaths in birds and mammals by raising their temperatures by 4 or 5 degrees celsius. He showed that the lesions found at autopsy were similar to that noted in heatstroke and considered the cause of death to be due to purely physical causes (5).

Other investigators however agreed with De Meyserey and believed in an effect solely due to the sun's rays. In 1826 John Davy (4), an assistant director of army hospitals, wrote of an investigation of the sun's ability to penetrate the cranium. Using a dried skull bone in his experiment he concluded: 'when the sun's rays are concentrated by a lens, they penetrate...... through bone, through nine folds of black crepe and through rolled platinum. It was easy to ascertain their penetrating the former substance by a luminous point appearing on the surface beneath. This circumstance may help explain the effect of the sun on the brain, in producing a malady commonly called coup-de-soleil.' The property ascribed to these rays was termed 'actininc.'

With the expansion of British influence in India doctors of the Indian Medical Service were conducting their own research. A synopsis of 16 cases of heat apoplexy was reported in 1858 from the 19 Regiment. The Regimental doctor observed that these cases occurred when theo environment was hot and dry. The dry bulb temperature was greater than $97^{\circ} \mathrm{F}$ for all the cases, seven of whicho were fatal. He recommended a treatment of 'a cold". affusion by mussucks of water poured over head, chest $\overrightarrow{\vec{F}}$ and spine, purgative enemata and blistering to the nape of the neck' (6). A similar series of 30 cases was reportedo the following year. It was noticed that these cases $\overline{\bar{c}}$ occurred during "sultry and oppressive weather with theक temperature between $94^{\circ} \mathrm{F}$ and $102^{\circ} \mathrm{F}$. It was hypothesised that the cause was 'excessive heat of the atmosphere acting on the young and unseasoned soldier whose system. was rendered more susceptible of such influence by moral $\overrightarrow{\vec{H}}$ and physical causes than in operation' (7).

The pervading theory on the causation of heatstroke taught to the British Army was that it was an affliction of the nervous system induced by heat, of which there were? three forms; the cardiac, the cerebrospinal and mixed. An example quoted in the lecture notes of the time was the experience of the 98th Regiment in capture of Chinkiangfoo during the China war. The unit had arrived fresh fromo UK and was committed to battle the day after arrival.s Before the soldiers reached the summit of the hill, 15 digdfrom heatstroke and many others succumbed during tofeo night (8).

By the end of the 19th century a raised cope@ temperature had been generally accepted as the primay physical sign of heatstroke. However there was stglos confusion regarding the exact diagnostic labels to app The Second Decennial Revision (1909) of te. internationally adopted Bertillion Classification of Causes of Death listed under Effects of Heat - coup-de-soleil, heat apoplexy, heat exhaustion, heat prostration, heato stroke, insolation, solus ictus, sunstroke, thermic fevero and thermoplegia as diagnostic labels (9).

The first investigator to establish a relationship between a measurement of environmental temperature and human core temperature was Haldane in 1905 (10). He subjected:himself and another subject to different temperatures and humidities whilst performing a range of activities. He demonstrated that the rise in rectal temperature correlated? with the wet bulb temperature better than the dry bulbत् temperature (DBT). He proposed that the limit of WBT that the body could tolerate at rest was $88^{\circ} \mathrm{F}\left(31.1^{\circ} \mathrm{C}\right)$ ato rest but this was reduced to about $78^{\circ} \mathrm{F}\left(25.5^{\circ} \mathrm{C}\right)$ when undergoing hard work.

The British Army at the turn of the century had many? troops deployed throughout the globe and heatstroke waso a major cause of illness in tropical stations. This provided ample opportunity to study the causes of heatstroke. Tableo 1 shows the admission rates for the British Army from 1902 to 1911 (11).

Rogers in 1908 produced the first comprehensive study $N_{0}$ demonstrating an association between cases, season and ${ }^{N}$ humidity (12). His study was based upon admissions to hospital in India. However, he differentiated betweeno 
TABLE 1

Cases Per Year (British Army) (8)

\begin{tabular}{lrrrrrrrrrr}
\hline Year & 1902 & 1903 & 1904 & 1905 & 1906 & 1907 & 1908 & 1909 & 1910 & 1911 \\
UK admissions & 14 & 6 & 23 & 18 & 48 & 13 & 43 & 8 & 13 & 53 \\
Total admissions & 247 & 390 & 407 & 517 & 476 & 253 & 282 & 174 & 145 & 328 \\
Total deaths & 52 & 61 & 38 & 60 & 43 & 16 & 40 & 17 & 7 & 26 \\
\hline
\end{tabular}

former were produced by the direct action of the sun and were often aided by excessive exertion such as when troops marched on a hot day. The latter following prolonged exposure to high atmospheric temperature with or without exercise and might occur without actual exposure to the sun e.g. stokers in a hot engine room. Thus he demonstrated the association between environmental heat and heatstroke but still believed in an effect produced by the rays of the sun in soldiers exercising in the heat.

Concurrently, Duncan presented a paper at the United Services Medical Society (13). He reviewed the theories for the effects of the sun, the actinic, the microbial, the toxic and the caloric. The evidence for the actinic theory was primarily based on studies conducted by an engineer, Colonel Maude. He asserted that the effect would pierce through anything except a layer of colour, particularly dark red and yellow. The effect had to be due to a unique action of the sun's rays because no one became affected by heat when luminous rays possess no degree of chemical energy, e.g. in a furnace. Furthermore ultraviolet and violet rays can produce a superficial dermatitis and cause pigmentation of the skin. Anecdotally he claimed that by adding a lining of orange red flannel to his helmet, wearing an orange coloured flannel shirt and having an orange-red pad sewn into his khaki coat over the spinal column he never once experienced any bad or distressing effects of the sun. This was recommended to his patients who, as far as could be gathered, found similar results. Colonel Maude further claimed proof from a particular episode when he lived in the same bungalow as another officer. One day this man surreptitiously abstracted the red lining from Maude's helmet. Maude had occasion to go out into the hot sun on duty that day and was again knocked over by the effects of the sun. He suspected that his theory might not be true until he was informed by the repentant officer of what he had done.

The microbe theory of Manson and Sambon proposed in 1898 was based on circumstantial evidence that fitted with current concepts of infectious disease (14). They claimed that the areas endemic for heat illness were strictly limited to the lowest regions, in coastal districts and in the valleys of the great rivers in the tropics. This fitted the geographical distribution of an infectious disease. Their studies found that cases did not especially occur with the hottest days and occurred mostly at night. Furthermore the suddenness of onset was analogous with suddenness of onset with many infectious diseases. Their evidence however did not accord with the statistics available from India. There were cases reported occurring at altitude and Rogers had demonstrated an association with meteorological conditions. Also when blood from sufferers of heatstroke has been injected into a health volunteer no reaction results. This also refuted the toxi theory. Finally if a man had had an episode of sunstrok he should be less liable to a subsequent attack if it was a infectious disease whereas in reality once a man has had an attack of sunstroke he was for ever afterwards molo liable to subsequent attacks. The caloric theory hạ already been described. After discussion the actinic theor was generally adopted by the military medical authoritio and heatstroke and sunstroke were accepted as disting diseases (13).

At the same time the RAMC was conducting research into the effect of exercise on soldiers. One course $\mathscr{A}$ experiments conducted in Aldershot in 1908 measureâ rectal temperatures of soldiers after performing a series मृ forced marches (15). This study demonstrated that exercising in the heat caused a marked loss of watep through sweating. It concluded that the temperature of the body was raised considerably by marching and therefors marching was an important factor in the causation heatstroke. Adverse factors causing this were a high temperature, moist air and the absence of wind delaying evaporation of sweat. The influence of practice was demonstrated by an improvement measured over a 3 we 8 training period. The following recommendations $f(g$ training were made: 'officers commanding should enșara marching was performed with an open jacket and sQifQ the load carried and distance marched shouldis? progressively graduated and smoking in the ranks shig be discouraged.'

A comprehensive review of the causes of 'the effects heat' during the South African War of October 18 응. May 1898 was reported in 1909 (16). During this watetge total admissions of all ranks were 1,625 with 15 de and 325 invalided from the country. This gave 2 incidence of $2.68 / 1000$ for the war. There was a cle seasonal distribution with the peak incidence during t18 summer months of October to March. However, the mos

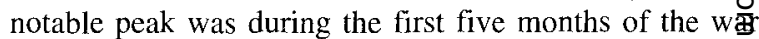
which coincided with both the hot months and the mo표 intense military operations. During this period troo were involved in the advance to Natal and the relief of Ladysmith, the advance into the Transvaal, the relief Kimberley and the advance into Bloemfontein. Although an attempt was made to correlate the incidence of hest casualties with the meteorological conditions the recors were insufficiently complete to achieve this.

In addition to British work, studies were being reporteg in the German Army. A review on the prevention of sunstroke (17), divided the causes into 3 group atmospheric influences, military duties and individuat predisposition. German work supported the view that the environmental effect was due to a combination of he and humidity. German Army Field Service Regulation (18) considered the great enemy of infantry on the marche to be the heat. It was recommended that a trial marole should be undertaken before summer manoeuvres to detect any soldiers who might be liable to devel sunstroke. 
The Manual of Elementary Military Hygiene published in 1912 contained advice for military medical officers on the prevention of disease (19). The following is an extract relating to the effects of heat. 'Heatstroke is a great rise in body-temperature to $106^{\circ} \mathrm{F}\left(41.1^{\circ} \mathrm{C}\right), 107^{\circ} \mathrm{F}\left(41.6^{\circ} \mathrm{C}\right)$ or even $109^{\circ} \mathrm{F}\left(42.2^{\circ} \mathrm{C}\right)$, coming on during a very high atmospheric temperature, whether the heat is natural or artificial. The term 'sunstroke' was usually applied to heatstroke due to exposure to hot sun. The principle measures of prevention consist in avoiding the least excess of alcohol and eating, especially red meat. During marches in hot weather the weight carried should be reduced to a minimum, the most open order practicable should be allowed and halts should be frequent, coats and shirts should be worn open. It should not be confounded with heat-exhaustion, which is merely a form of fainting from which men are apt to suffer when marching in a hot climate. It is a common fault, even amongst experienced soldiers, to take too free recourse to the contents of their water bottles and a tendency to drink each time they approach water. Endeavours should be made to develop a proper sense of water self discipline.' No mention in the manual is made of the actinic theory or the elaborate precautions being proposed to reduce the actinic effects. Troops serving in hot climates were all issued with helmets with red liners and also thick quilted pads to place over the spine to protect the spinal cord.

There were many who disbelieved in the unique effects of the sun. The German physiologist Hans Aron working in Manilla reported a series of animal experiments (20) in which a comparison was made between monkeys exposed to sunlight and cooled by fans and monkeys exposed to sunlight and not cooled by fans. The control animal died within 58 minutes whereas the cooled animals showed only a slight rise in body temperature after several hours. At the same time the US Army was conducting research into the protective value of orange-red underclothing (21). Five hundred soldiers serving in the Philippines were issued the special clothing and compared with 500 controls. There was no difference between the two groups in those reporting sick, blood examinations or impressions of the wearer.

Pembrey, in a study of 50 heat stroke victims in India, reported in 1913, demonstrated the following associations with heatstroke: exposure to high and moist atmosphere, muscular work, unsuitable clothes, heavy loads, debility due to alcohol and other causes. From his analysis he concluded 'the actinic rays of the sun were only an indirect factor in the causation of heatstroke. The white man is forced to protect the skin from the action of the sun's rays by clothing, he sweats extravagantly and much of the moisture is absorbed by clothing and not directly used by the body for cooling by evaporation.' (22)

Wanhill conducted a course of experiments in India in 1914 to determine the relative value of red linings for helmets (23). Four helemts were used, 2 with red linings and 2 with ordinary linings into which was placed an ordinary clinical thermometer. These were placed in the open sun and the internal temperatures recorded. There was no variation in the temperature measured inside the helemets between those with a red lining and those with an ordinary lining.

Simpson, in 1914, was the first investigator to demonstrate an experimental correlation between the incidence of heat casualties and WBT (24). Indeed his methodology of plotting the incidence of heat casualties against the environmental temperature is a recurring theme. The developing consensus through the pages of the Journal of the Royal Army Medical Corps was that heatstroke was the result of a raised core temperature consequent to a breakdown in the body's cooling system. The effects of environmental heat depended on the temperature and the humidity of the air which determined the efficiency of sweating to cool the body. The best measure of environmental heat load was the wet bulb temperature which combined the temperature and humidity of the environment into a single measure.

\section{World War 1 and Interwar Years}

The First World War was characterised by conflict in many different parts of the globe. Although the primary conflict was based on Western Europe, the British Army was in action in many hot climates. Table 2 shows the admission rates for the effects of heat for the British Army in World War 1 (25). The high incidence in Macedonia, Mesopotamia and India is clear.

In Mesopotamia, Macedonia and South-West Africa admissions due to the effects of heat were of major importance to military commanders. There was inevitably< a seasonal variation in hospital admissions for the effects of heat which is clearly shown in the total monthly admissions for Mesopotamia for 1917 and 1918 (Fig 1)ọ These statistics cannot demonstrate the true effects of heaf on military operations in Mesopotamia. For example in the assault on Ramadi in July 1917 there were 60 British and 120 Indian wounded and 150 British and 250 Indian casualties from the heat from a column composed of one British battalion and two Indian battalions and supporting arms, a total of approximately 2000 soldiers (26).

By 1917 extensive precautions were taken to reduce the effects of the heat in Mesopotamia. Heatstroke stations were authorised on a scale of ten per division with additional stations for each hospital centre, base or post on the lines of communication. These were constructed of reed matting with open sides. The roof was made of double or triple matting layers to insulate from the heat. Ice was provided daily at a scale of $40 \mathrm{lb}$ per station. Troops were relieved of duty as far as possible beween 10 am and $4 \mathrm{pm}$. There was an abundant supply of drinking water in base areas and each man was issued with a onegallon canvas water bottle (chagul) in which water was cooled by evaporation. Troops arriving were given lectures and demonstrations about preventive health measures. Special instructions were issued in army orders on the individual measures to be taken to mitigate the effects of heat and warning of the risks of alcohol and other predisposing conditions (26). The cumulative British experience of the effects of the heat was published 
Table 2

Admissions to Hospital for the Effects of Heat (World War I) (25)

\begin{tabular}{|c|c|c|c|c|}
\hline Admissions & Admissions per 1000 strength & Total Deaths & Theatre & \\
\hline 1528 & 2.75 & 13 & South African War 1899-1902 & \\
\hline 686 & 5.86 & 0 & Dardenelles & \\
\hline 262 & 0.18 & 0 & France 1915 & \\
\hline 6 & 0.1 & 0 & Macedonia Oct-Dec 1915 & \\
\hline 452 & 3.66 & 4 & Macedonia 1916 & \\
\hline 44 & 0.24 & 0 & Macedonia 1917 & \\
\hline 4 & 0.3 & 0 & Macedonia 1918 & \\
\hline 506 & 1.26 & & Macedonia Oct 1915-Dec 1918 & \\
\hline 538 & 77.39 & 1 & Mesopotamia. Nov 1914-Dec 1915 & British Troops \\
\hline 2459 & 51 & 0 & Mesopotamia 1916 & British Troops \\
\hline 6242 & 74.4 & 524 & Mesopotamia 1917 & British Troops \\
\hline 574 & 5.35 & 31 & Mesopotamia 1918 & British Troops \\
\hline 9813 & 38.22 & & Mesopotamia. Nov 1914-Dec 1918 & British Troops \\
\hline 52 & 2.09 & 0 & Mesopotamia. Nov 1914-Dec 1915 & Indian Troops \\
\hline 56 & 0.48 & 0 & Mesopotamia 1916 & Indian Troops \\
\hline 896 & 4.01 & 89 & Mesopotamia 1917 & Indian Troops \\
\hline 172 & 0.57 & 14 & Mesopotamia 1918 & Indian Troops \\
\hline 1176 & 1.68 & & Mesopotamia. Nov 1914-Dec 1918 & Indian Troops \\
\hline 406 & 12.3 & 1 & South-West Africa & \\
\hline
\end{tabular}

by the War Office in the 'Memoranda on Medical Diseases in Tropical and Sub-Tropical Areas' in 1919 (27). It was considered that heatstroke was an autointoxication caused by lack of escape of heat from the body due to insufficient evaporation from the skin and the effects of muscular fatigue, heat exhaustion only occurring in heavily laden men on the march in hot weather.

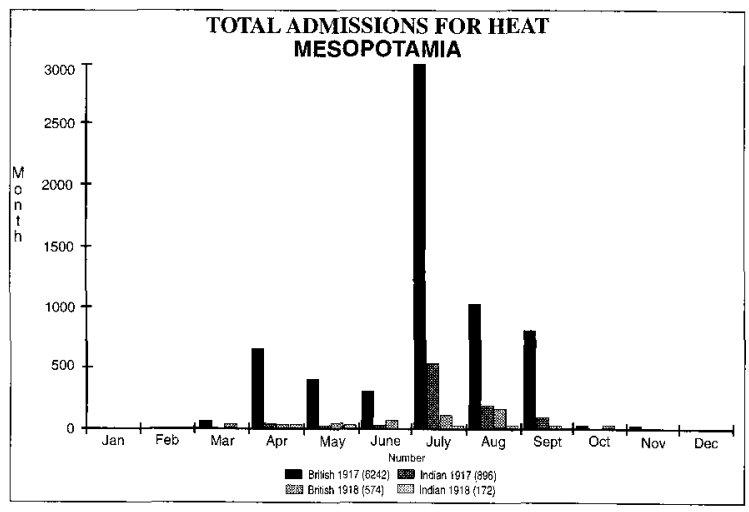

Fig 1

A detailed analysis of the military medical experience in Mesopotamia was published in the British Medical Journal in $1920(28,29)$. There was a clear association between the maximum DBT and the incidence of cases of heatstroke. More importantly there seemed to be a cumulative effect whereby the peak of admissions for heatstroke was delayed by one or two days from the onset of a heatwave. The effect of high humidity was suggested by an increased incidence at Basrah compared to Baged where the relative humidity was less. This effect wasion 8 demonstrated by meteorological records. There wa? evidence of any 'actinic' effect of the sun's rays. Tles primary additional risk factor for heatstroke was exe⿳igi particularly if heavy equipment was carried. This further compounded on operations if adequate drin water was not available. These factors caused the lara numbers of casualties during the operation to captude Ramadi. Other risk factors identified were increasing ago, race (Indians had a lower incidence compared to Britis soldiers), alcohol, constipation and concurrent infectio disease. In Mesopotamia the intense dry heat seemed to exhaust the sweating mechanism in certain individuar particularly those with concurrent disease, and these patients were at especial risk of heatstroke. Hearne, physician working in Basra, described touring his wards at hourly intervals on hot days to feel the skin of his patients. Those who had stopped sweating were imminent danger of developing heatstroke. Their rec temperatures were measured and those with a temperatuige greater than $103^{\circ} \mathrm{F}\left(39.4^{\circ} \mathrm{C}\right)$ were stripped naked, covere with a wet sheet and placed under a fan. This wos continued until the temperature had returned to normal and sweating restarted (29).

These observations were reinforced by further repons from Basra in 1922 (30), Allahabad in 1930 (31) aiti Bagdad in 1932 (32). The prevailing opinions amongst British commentators were reviewed in 1939 by Nicholls (33). He reiterated that amongst soldiers the primas cause of heatstroke was physical exercise in hot weathen It could be prevented by adequate water, salt and rest. Ft $_{1}$ was more common in the constipated, those who abus 
alcohol and those already ill. Most medical commanders issued local instructions for the prevention of heatstroke. One such example required medical officers to ensure that there was adequate cool drinking water for their trooops. Men with fever, headache, constipation or dry skin were required to report sick. There was also an explicit instruction on the treatment of heatstroke (34).

Concurrent to these British studies researchers in the United States were also investigating the causes the effects of heatstroke. The creation of a single index incorporating all temperature readings that would summarise environmental heat was also of interest to heating and ventilation engineers. An index was developed empirically by subjecting volunteers to different combinations of DBT, WBT and humidity in 1927. This was called the Effective Temperature index (ET) (35). The only epidemiological study was a review of the heat casualty reports for the United States Navy which found that there had been 38 deaths and 43 invalided from the service from 1861 to 1926 (2). The main finding was a marked increased risk between those born in the north of the United States compared with those who were born in the south, which suggested that living in a hot environment conferred some protection from the development of heat illness.

In summary the consensus view prior to the Second World War was that heatstroke and heat exhaustion were a consequence of exposure to high environmental temperature. Although there was no evidence of any direct effect of the sun's rays in the development of heatstroke the use of solar topees as head protection and spinal pads to protect the spine was still advocated by many authorities. The protective value of exposure to hot climates (acclimatisation) was understood but the physiological effects of this had been investigated.

\section{World War II and Related Research \\ Operational Experience}

The effect of heat on British operations during World War II was less than in World War I. During 1914-18 the emphasis was on special clothing, limited work routines and creating cooling accommodation. During the Second World War the emphasis was on acclimatisation and the provision of adequate water, salt and sleep. Considerable efforts were made to educate individual soldiers, unit commanders and medical officers about the effects of heat and the prevention and treatment of heat illness. In spite of the deployment of troops to North Africa, Abyssinia, Syria, India and the Far East it was only in the Persia and Iraq theatre that there was a substantial drain on manpower from heat illness (Table 3).

Inevitably lessons from the First World War were relearnt. In Persia and Iraq there were, 2,964 admissions between May - September in 1942 (37). From this number $65 \%$ were newly arrived and of these $65 \%$ occurred on board ship or shortly after disembarkation. Heatstroke outbreaks could often be traced to ignorance and lack of initiative on the part of regimental officers. An example quoted from 'Service in Hot Climates: a pamphlet for
Table 3

Annual Admission Rates per Thousand Strength by Region (Commonwealth Troops) (36)

$\begin{array}{cl}2.8 & \text { Middle East Forces } 1942 \\ 0.54 & \text { Middle East Forces 1943 } \\ 0.24 & \text { Middle East Forces 1944 } \\ 0.51 & \text { Middle East Forces 1945 } \\ 5.37 & \text { Sudan 1942 } \\ 3.61 & \text { Sudan 1943 } \\ 1.51 & \text { Sudan 1944 } \\ 0.9 & \text { India 1936 } \\ 1.1 & \text { India 1937 } \\ 2 & \text { India 1938 } \\ 2.3 & \text { India 1939 } \\ 6.1 & \text { India 1940 } \\ 7.8 & \text { India 1941 } \\ 19.7 & \text { India 1942 } \\ 5.3 & \text { India 1943 } \\ 7.4 & \text { India 1944 } \\ 12 & \text { India 1945 } \\ 88.7 & \text { Persia and Iraq 1942, British } \\ 3.2 & \text { Persia and Iraq 1942, Indian } \\ 11.5 & \text { Persia and Iraq 1943, British } \\ 0.3 & \text { Persia and Iraq 1943, Indian }\end{array}$

officers' (38) illustrates the point. 'An Indian dratio numbering 1,134 disembarked at a tropical port o morning in August. The ship had docked the previous evening, and the troops had spent the night between decks in the torrid heat of the docks. They disembarked at $04 \$ 0$ ) hours, marched to the station, entrained in goos waggons, and arrived at the Transit Area at 0900 hous Upon arrival, they were marched, carrying their kit, for nearly half a mile to their camp, where they had to draw and pitch their own tents. This was the last straw, weak $\underset{\mathscr{Q}}{\mathbb{Q}}$ with hunger, exhausted and overwhelmed by the heat, the $\vec{\overrightarrow{ }}$ men went down like ninepins, and one hundred cases 3 were admitted to hospital.' The chapter on the effects of heat in the 1942 edition of 'The Memoranda on Medicalof Diseases in Sub-Tropical Areas' had substantially changed since the 1919 edition (39). Heatstroke was now defined as an acute febrile state due to failure of the heat? regulating system. Heat exhaustion was attributed to as derangement of body chemistry. Risk factors were identified as high humidity, clothing concurrent illness, a previous attack and lack of fluid, food, salt, sleep and훅 acclimatisation. Temperatures above WBT $83^{\circ} \mathrm{F}\left(28.4^{\circ} \mathrm{C}\right) \frac{3}{.}$. were regarded as particularly dangerous. In spite of this itoํ was noted that cases could occur in England.

The Australian experience was similar and the preventive measures instituted matched those used by theo British (40). However, the Australian Army experienced an additional problem during the training of recruitso because many training camps were located in the hot areas of Queensland and Western Australia.

The most striking feature of the US Army experience was that the majolrity of heat casualties occurred withiro 
Table 4

Admissions to Hospital for Effects of Heat US Army 1942-1945 (41)

\begin{tabular}{|c|c|c|c|c|c|c|c|c|c|c|}
\hline Theatre & Total & $\begin{array}{l}\text { Rate } \\
\text { per } 1000\end{array}$ & $\begin{array}{l}1942 \\
\text { Total }\end{array}$ & Rate & $\begin{array}{l}1943 \\
\text { Total }\end{array}$ & Rate & $\begin{array}{l}1944 \\
\text { Total }\end{array}$ & Rate & $\begin{array}{l}1945 \\
\text { Total }\end{array}$ & Ra色 \\
\hline$\overline{\text { All }}$ & 35389 & 1.38 & 6579 & 2.03 & 17408 & 2.54 & 6941 & 0.89 & 4470 & 0.59 ? \\
\hline $\begin{array}{l}\text { CONUS } \\
\text { Outside CONUS }\end{array}$ & 26936 & 1.83 & 5852 & 2.2 & 14470 & 2.79 & 4299 & 1.08 & 2315 & 0.7 宽 \\
\hline Total & 8462 & 0.79 & 727 & 1.24 & 2938 & 1.74 & 2642 & 0.69 & 2155 & $0.4 \mathrm{~g}$ \\
\hline Europe & 231 & 0.05 & 4 & 0.05 & 8 & 0.03 & 70 & 0.04 & 140 & 0.0 ह \\
\hline N Africa*** & 987 & 0.67 & 2 & 0.09 & 716 & 1.57 & 204 & 0.31 & 65 & 0.1 递 \\
\hline Middle East & 1377 & 9.42 & 35 & 5.78 & 1104 & 20.82 & 158 & 3.41 & 80 & $1.9 Q^{\circ}$ \\
\hline China-Burma-India & 949 & 2.16 & 92 & 10.52 & 92 & 2.32 & 525 & 3.11 & 240 & 1.08 \\
\hline Southwest Pacific & 2891 & 1.58 & 122 & 1.72 & 386 & 2.03 & 1148 & 2.13 & 1235 & $1.2 \vec{\circ}$ \\
\hline Central \& S Pacific & 1238 & 0.98 & 174 & 1.15 & 460 & 1.58 & 399 & 0.91 & 205 & 0.54 \\
\hline North America & 26 & 0.05 & 8 & 0.08 & 4 & 0.02 & 4 & 0.03 & 10 & $0.1 \overrightarrow{\underline{W}}$ \\
\hline Latin America & 252 & 0.66 & 114 & 1.12 & 97 & 0.8 & 31 & 0.36 & 10 & 0.1 年 \\
\hline
\end{tabular}

the Continental United States (Table 4). This will be considered in more detail in the discussion on epidemiology. The reports from the Middle East included cases occurring in Iraq which represented a very high proportion of troops deployed. This mirrored the British experience in the same region reaching a maximum of 295.81 per 1,000 per annum in July 1943 (41). The preventive measures instituted for the summer of 1944 included a compulsory rest between 1200 and 1700 , cooled sleeping quarters and heatstroke centres, and education programmes. This led to a substantial reduction in incidence (41 per 1,000 in July 1944). In the ChinaBurma-India theatre heat casualties were only significant during June and July 1942 (70.80 per 1,000 per annum in June and 42,86 in July) when General Merrill's Marauders were conducting offensive operations against the Japanese. Within the South and Southwest Pacific heat illness assumed significant proportions during operations or strenuous training. During the fighting for Guadalcanal 141 patients were admitted to field hospitals between November 1942 and mid-February 1943. When compared to admissions for tropical illness, heat exhaustion ranked tenth as a cause for hospitalisation behind the prevalent infectious diseases. However hospital based statistics for the effects of heat during operations are probably unreliable as the evacuation time in most theatres was several hours by which time serious heatstroke casualties would have died. Mild cases would be expected to recover with cooling and rehydration and thus could be treated without hospital admission.

\section{Epidemiological Analyses}

Limited reports were written about British experience in Iraq $(42,43)$ which showed associations with heatstroke and maximum daily temperature, physical exertion and acclimatisation. However the majority of British research was involved with measuring the physiological effects of heat. The majority of the epidemiological analysis of heat casualties originates from the experience of the US Army in training camps $\$$ the United States. Excluding sunburn and burns, these were 26,936 admissions and 202 deaths from heat indhe Continental United States between 1942 and 1945 All of these were from military training camps. The eqgent of strict preventive measures that ensured adequate $\overrightarrow{\mathrm{g}} \mathrm{g}$ and water and avoided physical exertion in hot weather was reported from Fort Eustis, Virginia (44) and Keş्रु|er Field, Mississippi (45). In both series a signifigật reduction in cases was achieved by unit commanees ensuring strict adherence to the medical recommenda

Table 5

Limits for Physical Training Fort Eustis 1943 (44)

a. If the wind velocity is 10 miles per hour or over, the wet bulb temperature may go to $77 \mathrm{~F}(25.2 \mathrm{C})$ before limiting physical activity if the dry bulb temperature does not exceed $88 \mathrm{~F}(31.1 \mathrm{C})$

b. Wind a wind velocity below 5 miles per hour (decreased mean of heat loss by convection), if the wet bulb temperature reaches $\frac{5}{2}$ $(23.9 \mathrm{C})$ to $76(24.8 \mathrm{C})$ degrees a dry bulb temperature of $88 \mathrm{~F}$ $(31.1 \mathrm{C})$ is considered maximum for continuation of full physical activity.

c. A wet bulb temperature of $78(25.6 \mathrm{C})$ to $79(26.2 \mathrm{C})$ degrees with a wind velocity below 10 miles per hour is considered to be the danger point for any physical activity if the dry bulb temperature is $88 \mathrm{~F}(31.1 \mathrm{C})$ or above.

for prevention of heat casualties. The measures introduce्g1 at Fort Eustis included the first attempt to correlate preventive measures with an index of environmental temperature (Table 5).

An analysis of fatal cases of heatstroke was al undertaken $(46,47)$. The majority of patients reported hof been engaged in some form of military exercise, such long marches, drill or target practice. Although the effect of heatstroke did not always occur during the activif there seemed to be a direct association. The distribution \&f deaths was also analysed according to length of time 
service and length of time serving in a training camp in the Southern United States. It was found that $57.8 \%$ of cases occurred in soldiers who had spent less than 4 weeks in the South, $17.2 \%$ had spent 5-8 weeks, $12.5 \%$ had spent 9-12 weeks and $12.5 \%$ had spent over 12 weeks. This supports the evidence for the protective effects of acclimatisation which takes approximately 4 weeks. The local meteorological records were sought for the time of each heat related death and these were plotted for DBT and humidity. From this a line representing the critical environmental limits for heatstroke could be drawn which could represent the danger limits for healthy unacclimatised young men. This line goes through a point WBT $75^{\circ} \mathrm{F}\left(23.9^{\circ} \mathrm{C}\right)$, DBT $75^{\circ} \mathrm{F}\left(23.9^{\circ} \mathrm{C}\right)$ at $99 \%$ humidity to WBT $78^{\circ} \mathrm{F}\left(29^{\circ} \mathrm{C}\right)$, DBT $110^{\prime \prime} \mathrm{F}\left(43^{\circ} \mathrm{C}\right)$ at $7 \%$ humidity. An association between obesity and death from heatgstroke was also found. Overall it was found that deaths associated with heavy exercise occurred at temperatures when the total heat load is commonly underestimated.

During World War II each of the allies conducted extensive research into the physiological aspects of working in hot environments. The casualty statistics suggest that heat illness was a problem that occurred principally during training and not during operations. However, it is not possible to establish the true incidence of heat casualties occurring during training outside the United States. It is possible that heat casualties were considered by unit commanders to be an acceptable part of training for war. Therefore detailed reporting of cases may not been considered worthwhile.

The second part of this paper will demonstrate refinements in the techniques for the epidemiological analysis of heat casualties rates. This has led to more sophisticated guidelines for military training in heat. It will be seen that the predisposing factors for heat illness identified in the literature up to the end of the Second World War have been confirmed by more recent studies.

\section{REFERENCES}

1. BRAHAMS D. Legal and moral responsibilityfor heatstroke in the armed forces. Lancet 1989; ii: 814-815.

2. WAKEFIELD EG, HaLl WW. Heat injuries, a preparatory study for experimental heatstroke. JAMA 1927; 89: $92-95$.

3. A Roman experience with heatstroke in 24 BC. Bull NY Acad Med 1967; 43: 767-768.

4. Renbourn ET. The Spine Pad: a discarded item of tropical clothing. JR Army Med Corps 1956; 102: 217-233.

5. Hall WW, Wakefield EG. A study of experimental heatstroke. JAMA 1927; 89: 177-182.

6. LONGMORE T. A synopsis of 16 cases of heat apoplexy. Journal unknown. 1858; 396-407.

7. BUTLER JH. Report on the outbreak of insolation. Journal unknown. 1859; 407-423.
8. MCClEan WC. Diseases of Tropical Climates. Lectures at the Army Medical School London: Macmillan $\&$ Co 1886.

9. ElLIS FP. Heat illness. Trans RSoc Med Hyg 1976; 70: $402-425$.

10. HaLdANE JS. The influence of high air temperatures. J Hyg (Lond) 1905; 5: 494-513.

11. Pembrey MS. Heatstroke: further observations on an analysis of fifty cases. JR Army Med Corps 1914; 22: 629-638.

12. ROGERS L. The relationship of the temperature and moisture of the atmosphere to the incidence of heatstroke. JR Army Med Corps 1908; 10: 25.

13. DUNCAN A. Remarks on some recent theories on the action of heat in the tropics. JR Army Med Corps 1908; 11: 71 .

14. Manson P. Tropical Diseases. London: Cassell \& Co 1898.

15. Committee on the Physiological Effects of Food, Training and Clothing of the Soldier. Fourth report. JR Army Med Corps 1909; 12: 211-217.

16. SIMPSON RJS. The 'effects of heat' during the South African War. JR Army Med Corps 1909; 12: 243-263.

17. The Prevention of sunstroke. Reported in JR Army Med Corps. JR Army Med Corps 1909; 12: 351-353

18. MeLville CH. The physiology of the march. JR Arm Med Corps 1911; 17: 30-49.

19. Manual of Elementary Military Hygiene. HMSC WO1680 1912 pp. 11-12, 45-46.

20. Effects of the sun in the tropics. Reported in JR Army Med Corps. JR Army Med Corps 1911; 17: 316-180 o

21. Orange-red underclothing under test. Reported in JIF Army Med Corps. JR Army Med Corps 1911; 16흔 109-111.

22. PembreY MS. Heatstroke: further observations on an analysis of fifty cases. JR Army Med Corps 1914; 22: 629-638.

23. WANHILL CF. Factors which may influence the production of 'Heatstroke' among troops on the march or on service JR Army Med Corps 1914; 22: 661-664.

24. SIMPSON JS. Humidity and Heatstoke. JR Army Med Corps 1914; 23: 1-11.

25. Mitchell TJ, SMiTh GM. Medical services. History of the Great War. Casualties and Medical Statistics. London: HMSO 1931.

26. MacPherson WG, Mitchell TJ. Medical services general history Vol IV. London: HMSO 1924.

27. Memoranda on medical diseases in tropical and subtropical war areas. 3rd edition. London: HMSO 1919 pp95-99.

28. WILLCOX WH. The Nature, Prevention and the Treatment of Heat Hyperpyrexia: the clinical aspect. $\mathrm{Br}$ Med J 1920; 1: 392-397.

29. Hill L. The Nature, Prevention and the Treatment of Heat Hyperpyrexia: the physiological aspect. $\mathrm{Br} \mathrm{Med}$ $J$ 1920; 1: 397-399.

30. ALEXANDER RH. Notes on cases of heatstroke occurring in British troops stationed at Basra, Mesopotamia. JR Army Med Corps 1922; 38: 358-366. 
31. Hamilton CSP, Basu DN, van Haeften J. Review of cases of "Effects of Heat' occurring during the hot weather of 1929 at Allahabad. JR Army Med Corps 1930; 55: 120-125.

32. MORTON TC. The aetiology and treatment of heat exhaustion and heat hyperpyrexia, with special reference to experiences in Iraq. JR Army Med Corps 1932; 59: 200-211.

33. NiCHOLLS TB. Heatstroke and allied conditions. $J R$ Army Med Corps 1939; 72: 73-84.

34. HAUGHTON SGS. The effect of high temperatures on man. Personal papers. 1937/8.

35. YAGLOU CP. Temperature, Humidity, and Air Movement in Industries: The Effective Temperature Index. J Indust Hyg 1927; 9: 297-309.

36. MELlOR WF. Casualties and Medical Statistics. In Official Medical History of the Second World War. London: HMSO 1972.

37. CREw FAE. The Army Hygiene Service. In Volume II Official Medical History of the Second World War. London: HMSO 1955 pp 179-185.

38. The War Office. Service in Hot Climates. London: War Office, 1944.

39. Memoranda on medical diseases in tropical and subtropical areas. 7th edition London: HMSO 1942 pp 119-23.
40. WALKer AS. Clinical problems of war. Australia the War of 1939-1945 Series 5 Volume 1.

41. HofF EC, HoFF PM. Preventive medicine in Wor War II. In Vol IX Special Fields. Medical Departmeff United States Army. 1969 pp203-232.

42. HALLIDAY CROOM J. Effects of Heat: an account of group of cases admitted to a general hospital on arrival to the Middle East. JR Army Med Corps 194霜 83: 288-292.

43. Ladell WSS, Waterlow JC, Faulkner Hudson Desert climate: physiological and clinical observes tions. Lancet 1944; 6320: 491-497 and 527-531.

44. BORDEN DL, WADDILL JF, GRIER GS. Statistical study of 265 cases of heat disease. JAMA 1945; 17: 1200 . 1205.

45. WALLACE AW. Heat exhaustion. Milit Surg 1943; $9 \overrightarrow{\mathrm{z}}$ 140-146.

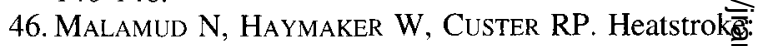
a clinicopathological study of 125 fatal cases. $M i \overline{\mathrm{O}_{\mathrm{O}}} t$ Surg 1946; 99: 397-449.

47. SCHICKLE E. Environment and fatal heatstroke. Mi $\overrightarrow{A t}$ Surg 1947; 100: 235-56. 